\title{
« Keeping Up with or Running Away from the Joneses: the Barro Model Revisited »
}

\author{
Auteur
}

Thi Kim Cuong Pham

Document de Travail $n^{\circ} 2018-29$

Juin 2018

\section{Bureau d'Économie}

Théorique et Appliquée

\section{BETA Université de Strasbourg}

Faculté des sciences économiques et de gestion

61 avenue de la Forêt Noire

67085 Strasbourg Cedex

Tél. : +33 (0)368 852069

Fax : +33 (0)3 68852070

Secrétariat : Géraldine Del Fabbro g.delfabbro@unistra.fr 


\title{
Keeping Up with or Running Away from the Joneses: the Barro Model Revisited
}

\author{
Thi Kim Cuong Pham* \\ Université de Strasbourg, Université de Lorraine, CNRS \\ BETA Strasbourg, France
}

June 2018

\begin{abstract}
This paper reexamines the Barro growth model in a context of individual preferences with consumption externality. Agents care about both consumption and social status, which is determined by their relative consumption in society. The results underline the individuals' preferences for status as a key role in explaining long term growth and welfare. In particular, a higher growth rate may correspond to a lower social welfare if increment in growth is explained by status-seeking accompanied by the keeping up with the Joneses. Furthermore, we discuss two public financing systems from the viewpoint of growth and welfare. If lump-sum tax always implies a higher growth rate, income tax may perform better in terms of welfare when government size becomes sufficiently large.
\end{abstract}

Keywords: Income tax, lump-sum tax, keeping up with the Joneses, public spending, running away from the Joneses, status-seeking.

JEL Classification: D90; H20; H54; O41

\section{Introduction}

The role of the public sector as a determinant of economic growth in the long term was stressed in the seminal paper of Barro (1990). Public spending is

*BETA, 61 avenue de la Forêt Noire, F-67085 Strasbourg, France. Email: kim.pham@unistra.fr; Tel.: +33 (0)3 688520 77; Fax.: +33 (0)368 852070 
financed by income tax or lump-sum tax and considered as an input in the production process. Unlike the Ramsey model and the simple $A K$ model, economic growth is not Pareto optimal in the Barro model because of public spending externality. The question of government expenditures, economic growth and welfare always arouse much interest in economic debates. Certain studies focus on endogenous policies (Glomm and Ravikumar, 1994, Pham, 2005), others on public financing rules, or welfare-maximizing versus growthmaximizing government size (Lau, 1995, Marrero and Novales, 2005). For instance, Glomm and Ravikumar (1994) showed that the government size chosen via a majority vote is lower than the growth-maximizing government size. A more recent analysis by Marrero and Novales (2005) included a wasteful and unproductive component of public expenditures in the Barro model. The authors showed that the presence of a significant level of wasteful public expenditure is a sufficient condition for income tax to lead to a higher growth and welfare than which are obtained under lump-sum tax.

The goal of this paper is to reconsider the implications of government expenditures and their financing rules for growth and welfare in the context of interdependent preferences. It should be noted that the relative standing hypothesis has recently been the object of a great deal of interest in the growth literature. For instance, Corneo and Jeanne (2001) showed that in the Solow growth model, status-seeking may be an engine of economic growth if the marginal status utility of relative wealth is sufficiently important. Nevertheless, using the Ramsey model without technical progress, Rauscher (1997) stressed that the quest for social status only affects transitional dynamics. Since consumption externality leads to sub-optimality, corrective tax programs are also the research question in several papers (Fisher and Hof, 2000, Wendner 2003, 2010, Goméz, 2006, etc.). Typical findings underline the necessity of a constant capital subsidy and/or consumption tax rate which increases or decreases over time. Liu and Turnovsky (2005), Turnovsky and Monteiro (2007) considered both the effects of consumption and production externalities on the economic performance and characterized the optimal taxation to correct the distortions in the context of inelastic or elastic labor.

In line with these analyses of relative standing effects on economic growth, our study emphasizes the role of the demand side. Indeed, in investigating economic growth as well as its determinants, economists usually consider independent preferences defined by an absolute individual utility which solely depends on individual consumption or wealth. However, several empirical 
works such as McBride (2001), Frijters et al. (2004), Luttmer (2005), Ferreri-Carbonell (2005) and Clark et al. (2008) shed light on the phenomenon of relative utility. In a discussion about welfare economics, $\mathrm{Ng}$ (2003) underlined the importance of relative standing such as relative income or relative consumption, as well as its effects on economic analysis. It should be noted that this idea of relative utility is already present in Adam Smith's Theory of Moral Sentiments. According to Adam Smith, an individual amasses wealth not only to satisfy her basic material needs, but also to improve her relative position in society. This behavior is motivated by the quest for social status, which brings about social esteem, respect, admiration, etc. Following these lines of reasoning, Duesenberry (1949) stressed that there is an imitation-effect in the consumption of individuals who belong to the same social categories.

Our paper assumes that a desire for social status leads individuals to care about their consumption relative to a reference level. Individuals feel jealous when observing a higher reference level of consumption. This status-seeking may be accompanied by a desire to keep up with or run away from the Joneses. Public spending as an input in the production process is financed by income tax or lump-sum tax. Focusing on growth and welfare, the purposes of this paper are thus twofold: i) to compare two public financing systems (income tax and lump-sum tax) from the viewpoint of growth and welfare, ii) to discuss the impact of status-seeking accompanied by the desire to keep up with or run away from the Joneses on growth and welfare.

The main results can be summarized as follows. First, when comparing the two public financing systems, we observe that if lump-sum tax always implies a higher growth rate, income tax may perform better in terms of welfare when government size is above a certain threshold. ${ }^{1}$ The latter depends on different factors from supply side as well as from individual preferences. Second, the results underline the individuals' preferences for status as a key role in explaining long terme growth and welfare. In particular, when individuals keep up with the Joneses, the two growth rates under income tax and lump-sum tax are increasing with status motive. However, increased economic growth may correspond to a lower social welfare. Then, the social comparison accompanied by the desire to keep up with the Joneses may improve economic growth, without necessarily making people happier.

The remainder of the paper is organized as follows. Section 2 characterizes an endogenous growth model with status-seeking. In Section 3, we analyze the

\footnotetext{
${ }^{1}$ The government size is defined as the ratio of public spending to income.
} 
decentralized economy under income tax and lump-sum tax financing public capital, as well as the comparison between two public financing systems on the basis of growth and welfare. Section 4 focuses on the effects of status concerns on economic growth and welfare. Section 5 concludes.

\section{A model with status-seeking}

Let us assume that the economy consists of numerous infinitely-lived identical individuals. The population size is constant over time and normalized to unity. Labor is exogenous and inelastic. The individual's intertemporal utility is:

$$
\int_{0}^{\infty} U(c, \bar{c}) e^{-\rho t} d t
$$

where $\rho$ is the constant rate of time preference, $c$ denotes individual consumption and $\bar{c}$ is the average consumption level. We assume that $U(c, \bar{c})$ is twice differentiable, increasing and concave in $c$. Individuals may feel either admiring $\left(U_{\bar{c}}>0\right)$ or jealous $\left(U_{\bar{c}}<0\right)$ when observing a higher level of $\bar{c}$ (Dupor and Liu, 2003). The jealousy is identified under the assumption that individuals have a preference for social status (Corneo and Jeanne, 1997, 2001, Brekke and Howarth, 2002, Long and Shimomura 2004, Pham, 2005). It is also identified in empirical findings which concern the relative utility (Frijters et al. 2004, Ferrer-i-Carbonell, 2005 and Clark et al. 2008). In this case, we can write the individual utility as $U\left(c, \frac{c}{\bar{c}}\right)$ depending on absolute consumption, $c$, and on the relative consumption $c / \bar{c}$, which is a measure of an individual's social status.

Besides, the externality imposed by the average consumption level $\bar{c}$ on the utility may influence the individual's marginal utility of his own consumption. Referring to Galí (1994) and Dupor and Liu (2003), we describe keeping up with the Joneses (KUJ) when $U_{c \bar{c}} / U_{c}>0$ and running away from the Joneses (RAJ) when $U_{c \bar{c}} / U_{c}<0 .^{2}$ For the sake of simplicity, we adopt the following function

$$
U(c, \bar{c})=\frac{\left(\frac{c}{\bar{c}^{s}}\right)^{1-1 / \sigma}-1}{1-1 / \sigma} .
$$

The presence of status externality $(s>0)$ is necessary to consider the desire to keep up with or run away from the Joneses. An individual keeps up with (or

\footnotetext{
${ }^{2}$ In a model with endogenous leisure, Dupor and Liu (2003) introduced the notion of keeping up with (or running away from) the Joneses when the marginal rate of substitution between leisure and individual consumption increases (decreases) with respect to the average consumption level.
} 
runs away from) the Joneses if the average consumption level exerts a positive (or negative, respectively) effect on the marginal utility of his own consumption. This corresponds to $\sigma<1$ or $\sigma>1$. For $\sigma=1$, the average consumption level has no effect on the marginal utility of individual consumption as the utility function becomes $\ln \left(\frac{c}{\bar{c}^{s}}\right)$.

Equation (2) may be rewritten so that it depends on absolute and relative consumption:

$$
U\left(c, \frac{c}{\bar{c}}\right)=\frac{\left(c^{1-s}\left(\frac{c}{\bar{c}}\right)^{s}\right)^{1-1 / \sigma}-1}{1-1 / \sigma} .
$$

Referring to the status-seeking literature, we consider $0 \leq s<1$. Parameter $s$ represents the weight the individual attaches to her social status. Its magnitude is empirically estimated in Johansson-Stenman et al. (2002), AlvarezCuadrado et al. (2012). ${ }^{3}$ Individual utility is increasing and concave in relative consumption. $^{4}$

Each individual produces a commodity from private capital $(k)$ and public spending $(G)$. Let us assume that public spending enters the production function as a pure public good. The production function is assumed to be homogeneous of degree 1 in private capital and public spending, both factors have positive and diminishing marginal product. Assuming a Cobb-Douglas form, the production specification for firm $i$ is:

$$
y=f(k, G)=A k^{1-\alpha} G^{\alpha}
$$

where $\alpha, \alpha \in(0,1)$ is constant elasticity of income with respect to public capital. $A$ is a positive technological scale.

Capital accumulation follows the standard form:

$$
\dot{k}=(1-\tau) f(k, G)-c-\delta k
$$

if public spending is financed by income tax ( $\tau$ is the corresponding tax rate), or

$$
\dot{k}=f(k, G)-c-\delta k-T
$$

\footnotetext{
${ }^{3}$ For example, Alvarez-Cuadrado et al. (2012) estimate the importance of the interdependence of preferences and habit persistence. The results suggest that households' preferences derive almost $25 \%$ of their consumption services from comparison between their consumption and that of their neighbours, and around 35\% from comparison between their current and past consumption. This implies that around $60 \%$ of individual satisfaction is from relative consumption.

${ }^{4}$ Using German panel (GSOEP) spanning the years 1984-2001 and considering life satisfaction as a proxy of individual utility, Vendrik and Woltjer (2007) found the concavity of individual utility in relative income.
} 
if public spending is financed by lump-sum tax $T$. Parameter $\delta, \delta \in[0,1]$, is the depreciation rate of capital.

The budget constraint of the public sector is balanced at each period, i.e. in the income tax case,

$$
G=\tau y
$$

and in the lump-sum tax case,

$$
G=T
$$

Notice that the ratio of public spending to income $G / y=\tau$ is positive and represents the government size.

There are two types of externalities in this economy. The first one is linked to public spending. Individuals calculate their private marginal product of capital considering public spending as a given. As individual investment increases private capital and then production, it leads to an increase in public spending if the government maintains a balanced budget (constant $G / y$ ). The second externality is linked to individual desire for social status accompanied by KUJ (or RAJ). An increase in individual consumption raises the average level of consumption and so diminishes the relative consumption of others. Additionally, an increase in the average level of consumption affects the individual's marginal utility of his own consumption.

\section{Growth in a decentralized economy}

\subsection{Growth rate with income tax}

Let us consider the decentralized economy where individuals neglect externalities. In the case of income tax financing public capital, the individual producer-consumer chooses consumption and private capital to maximize intertemporal utility function (1) subject to capital accumulation equation (5), given public spending $G$ and average level of consumption $\bar{c}$. The representative individual's optimization program is as follows:

$$
\begin{aligned}
& \max _{(c, k)} \int_{0}^{\infty}\left[\frac{\left(\frac{c}{\bar{c}^{s}}\right)^{1-1 / \sigma}-1}{1-1 / \sigma}\right] e^{-\rho t} d t \\
& \text { subject to }\left\{\begin{array}{l}
\dot{k}=(1-\tau) y-c-\delta k \\
y=f(k, G) \\
\text { given } \bar{c} \text { and } G .
\end{array}\right.
\end{aligned}
$$


The growth rate of the decentralized economy, noted as $\gamma^{e}$, is

$$
\gamma^{e}(\tau)=\frac{\sigma}{1-s+s \sigma}\left[(1-\tau) f_{k}^{e}-\rho-\delta\right]
$$

where $f_{k}^{e}$ is the private marginal product of capital, and written as:

$$
f_{k}^{e}=(1-\alpha) A^{\frac{1}{1-\alpha}} \tau^{\frac{\alpha}{1-\alpha}} .
$$

and the decentralized consumption-capital ratio is given by

$$
\left(\frac{c}{k}\right)^{e}=(1-\tau) A^{\frac{1}{1-\alpha}} \tau^{\frac{\alpha}{1-\alpha}}-\delta-\gamma^{e} .
$$

We note $\epsilon(s, \sigma)=\frac{\sigma}{1-s+s \sigma}$ as the effective intertemporal elasticity of substitution when accounting for status-seeking behavior. Its value increases (or decreases) with $s$ if individual preference exhibits the desire to KUJ (or RAJ, respectively), i.e. if $\sigma<1$ ( or $\sigma>1$ ).

In order to have equation (9) as the path of growth, the transversality condition and the condition of bounded intertemporal utility are needed. ${ }^{5}$ The first one is given by

$$
\lim _{t \rightarrow \infty} e^{-\rho t} \lambda_{t} k_{t}=0
$$

where $\lambda_{t}$, the current Hamiltonian multiplier, denotes the current shadow price of capital. We have $\lambda_{t}=c_{t}^{-\frac{(1-s+s \sigma)}{\sigma}}$. Equation (12) may be rewritten as

$$
\lim _{t \rightarrow \infty} c_{o}^{-\frac{(1-s+s \sigma)}{\sigma}} k_{o} e^{\left(-\rho+(1-s)\left(1-\frac{1}{\sigma}\right) \gamma^{e}\right) t}=0
$$

Hence, the transversality condition is satisfied so long as:

$$
-\rho+(1-s)\left(1-\frac{1}{\sigma}\right) \gamma^{e}<0
$$

We remark that for $\sigma<1$ (i.e. KUJ), the above condition is automatically satisfied. For $\sigma>1$ (i.e. RAJ), this condition is verified only if the private marginal product of capital verifies the following relationship:

$$
(1-\tau) f_{k}^{e}<\rho+\delta+\frac{\rho(1-s+s \sigma)}{(1-s)(\sigma-1)} .
$$

Regarding the condition of bounded intertemporal utility

$$
\lim _{t \rightarrow \infty} e^{-\rho t} U\left(c_{t}, \overline{c_{t}}\right)=0,
$$

\footnotetext{
${ }^{5} \mathrm{As}$ the utility function is concave in $c$ and the capital accumulation function is concave in $k$, then the first-order conditions of the Hamiltonian problem are also sufficient (Mangasarian, 1966).
} 
it can be rewritten as:

$$
\lim _{t \rightarrow \infty} e^{-\rho t} \frac{c_{t}^{(1-s)\left(1-\frac{1}{\sigma}\right)}-1}{1-\frac{1}{\sigma}}=0
$$

Similarly to the transversality condition, condition (17) is satisfied so long as (14) is verified.

\subsection{Growth rate with lump-sum tax}

For the case of lump-sum tax financing public capital, the individuals' optimization program does not change: the individual producer-consumer chooses consumption and private capital to maximize the intertemporal utility (1) subject to the capital accumulation equation (6), taking the public capital $G$ and the average level of consumption $\bar{c}$ as given. The growth rate under lump-sum tax, noted as $\gamma^{T}$ is given by:

$$
\gamma^{T}(\tau)=\frac{\sigma}{1-s+s \sigma}\left[f_{k}^{e}-\rho-\delta\right]
$$

where $f_{k}^{e}$ is given by equation (10), and the consumption-capital ratio is

$$
\left(\frac{c}{k}\right)^{T}=(1-\tau) A^{\frac{1}{1-\alpha}} \tau^{\frac{\alpha}{1-\alpha}}-\delta-\gamma^{T} .
$$

Regarding the condition of bounded intertemporal utility and the condition of transversality, they will be satisfied if the following condition is satisfied:

$$
-\rho+(1-s)\left(1-\frac{1}{\sigma}\right) \gamma^{T}<0
$$

\subsection{Income tax or lump-sum tax?}

This section focuses on a comparison between income tax and lump-sum tax from the viewpoint of growth and welfare. We remark that the relationship between the growth rate under income tax and government size $\tau$ is not monotonous because an increase of $\tau$ has two effects on the growth rate: a negative effect via income tax since the after-tax marginal product of capital decreases, and a positive effect via public spending since the marginal product of capital increases. We can therefore calculate the government size $\hat{\tau}$ that maximizes the decentralized growth rate. This value is actually equal to production elasticity of public spending, i.e. $\hat{\tau}=\alpha$. However, in the case of lump-sum tax, this tax does not affect the after-tax private marginal product 
of capital, nor does it affect capital accumulation. It can immediately reduce consumption. The growth rate under lump-sum tax is then increasing with the government size $\tau$.

As in the conventional model, our comparison between income tax and lump-sum tax in terms of growth will focus on the possibility for each kind of tax to give a decentralized growth rate equal or close to the optimal growth. To do so, we need to determine the optimal growth rate by resolving the social planner's optimization problem. In a centralized economy, the social planner directly chooses quantities of consumption, private capital and public spending to maximize the individual's intertemporal utility while accounting for externalities. If we consider a social planner respecting individual preferences and forming her social objective on the basis of the same preference set as individuals, this situation means that individuals and social planner consider the same value of $s, s \in[0,1)$, when they make their decisions. ${ }^{6}$

In this case, the optimal growth rate to which we compare our decentralized growth rates would be:

$$
\gamma^{o}=\frac{\sigma}{1-s+s \sigma}\left[(1-\tau) f_{k}^{o}-\rho-\delta\right]
$$

where $f_{k}^{o}$ is the social marginal product of capital, always higher than the private marginal product of capital $f_{k}^{e}$ (equation (10)), and written as:

$$
f_{k}^{o}=A^{\frac{1}{1-\alpha}} \tau^{\frac{\alpha}{1-\alpha}} .
$$

given $G / y$ constant, and then $G / k$ constant. The optimal consumption to capital ratio is given by:

$$
\left(\frac{c}{k}\right)^{o}=(1-\tau) A^{\frac{1}{1-\alpha}} \tau^{\frac{\alpha}{1-\alpha}}-\delta-\gamma^{o} .
$$

The relationship between the optimal growth and the government size $\tau$ is characterized by an inverted U-shape. The maximum value of the optimal growth is reached when the government size $\hat{\tau}=\alpha$ is chosen. ${ }^{7}$

\footnotetext{
${ }^{6}$ However, the social planner does not necessarily need to incorporate status concerns in her social objective. A non-welfarist social planner can calculate the optimal growth on the basis of another set of preferences, ignoring status concerns. In this case, individuals may attach a weight $s>0$ to social status while it is considered as null by the non-welfarist social planner. In this case, the optimal growth rate is that of the status externality free-centralized economy as shown in Rauscher (1997), Corneo and Jeanne (1997).

${ }^{7}$ Combining (21) with (22), we can rewrite the optimal growth rate as $\gamma^{o}=$ $\frac{\sigma}{1-s+s \sigma}\left[(1-\tau) A^{\frac{1}{1-\alpha}} \tau^{\frac{\alpha}{1-\alpha}}-\rho-\delta\right]$. The FOC for a maximum value of $\gamma^{o}$ is $\frac{\partial \gamma^{o}}{\partial \tau}=$
} 
Proposition 1 Considering a decentralized economy where individual preference does exhibit the desire for social status and economic growth rate under income tax is defined by equation (9) while economic growth rate under lumpsum tax is defined by equation (18),

(I) The growth rate under lump-sum tax is higher than the growth rate under income tax. In particular, if the government size $\tau$ is optimally set $(\tau=$ $\hat{\tau})$, then the growth rate under lump-sum tax may reach the maximum value of the optimal growth.

(II) However, the social welfare coresponding to the growth rate under lumpsum tax is not necessarily higher than the social welfare corresponding to the growth rate under income tax.

Proof 1 (I) When comparing the decentralized growth rate under income tax $\gamma^{e}$ (equation (9)), with the decentralized growth rate under lump-sum $\operatorname{tax} \gamma^{T}$ (equation (18)), we observe that the first one is lower than the second one due to the fiscal distorsion in case of income tax.

Furthermore, the maximum value of the optimal growth is reached when the government size is optimally set, i.e. $\tau=\hat{\tau}$. For a Cobb-Douglas production, we obtain $\hat{\tau}=\alpha$. The maximum value of the optimal growth rate is given by:

$$
\gamma_{\max }^{o}(\hat{\tau})=\frac{\sigma}{1-s+s \sigma}\left[(1-\alpha) A^{\frac{1}{1-\alpha}} \alpha^{\frac{\alpha}{1-\alpha}}-\rho-\delta\right] .
$$

When evaluating the decentralized growth rates under lump-sum tax (equation (18)) and under income tax (equation (9)) for the case $\tau=\hat{\tau}$, we observe that the first one is equal to the maximum value of the optimal growth rate (equation (24)) while the second one is not.

(II) Focusing now on the comparison between two tax systems financing public spending in terms of social welfare, let us consider the intertemporal utility function (1) with the instantaneous utility given by equation (2). We write it in a reduced form by using the fact that $c$ rises at a rate of $\gamma_{j}$ and $c_{t}=c_{o} e^{\gamma^{j} t}, j=e, T$ :

$$
U^{j}=\frac{c_{o}^{(1-s)\left(1-\frac{1}{\sigma}\right)}}{1-\frac{1}{\sigma}}\left[\frac{1}{\rho-(1-s)\left(1-\frac{1}{\sigma}\right) \gamma^{j}}\right]-\frac{1}{\left(1-\frac{1}{\sigma}\right) \rho}
$$

$\overline{\frac{\sigma A^{\frac{1}{1-\alpha}}}{1-s+s \sigma}\left[-\tau^{\frac{\alpha}{1-\alpha}}+\frac{\alpha}{1-\alpha}(1-\tau) \tau^{\frac{\alpha}{1-\alpha}-1}\right]}=0$. It is satisfied when $\hat{\tau}=\alpha$. Notice that the second derivative of $\gamma^{o}$ with respect to $\tau$ is negative for $\tau=\hat{\tau}$. This confirms that $\hat{\tau}=\alpha$ is the government size maximizing the optimal growth rate. 
where $\rho-(1-s)\left(1-\frac{1}{\sigma}\right) \gamma^{j}>0$ following the transversality condition (14). As the initial consumption $c_{o}$ is a function of initial capital and growth rate, it may be computed following (11) under the income tax system:

$$
c_{o}=\left[(1-\tau) \tau^{\frac{\alpha}{1-\alpha}} A^{\frac{1}{1-\alpha}}-\delta-\gamma^{e}\right] k_{o} .
$$

Also, under the lump-sum tax system, $c_{o}$ may be computed following (19):

$$
c_{o}=\left[(1-\tau) \tau^{\frac{\alpha}{1-\alpha}} A^{\frac{1}{1-\alpha}}-\delta-\gamma^{T}\right] k_{o} .
$$

By plugging $c_{o}$ given by (26) in (25) and by using equations (10) and (9), we obtain a utility function for the case of income tax:

$$
U^{e}(\tau)=\frac{k_{o}^{\beta}\left(\phi \gamma^{e}(\tau)+\alpha \delta+\rho\right)^{\beta}}{(1-\alpha)^{\beta}\left(1-\frac{1}{\sigma}\right)\left(\rho-\beta \gamma^{e}(\tau)\right)}-\frac{1}{\left(1-\frac{1}{\sigma}\right) \rho}
$$

where $\beta=(1-s)\left(1-\frac{1}{\sigma}\right), \phi=(1-s)\left(\frac{1}{\sigma}-1\right)+\alpha$

Using $c_{o}$ given by (27) combined with equations (10) and (18) we obtain a utility function for the case of lump-sum tax:

$$
U^{T}(\tau)=\frac{k_{o}^{\beta}\left(\phi \gamma^{T}(\tau)+\alpha \delta+\rho-\tau \omega\right)^{\beta}}{(1-\alpha)^{\beta}\left(1-\frac{1}{\sigma}\right)\left(\rho-\beta \gamma^{T}\right)}-\frac{1}{\left(1-\frac{1}{\sigma}\right) \rho}
$$

where $\omega=\left(\frac{1-s}{\sigma}+s\right) \gamma^{T}(\tau)+\rho+\delta$ and $\gamma^{e}(\tau), \gamma^{T}(\tau)$ depending on $\tau$ are defined by equations (9) and (18), respectively.

When comparing $U^{T}$ and $U^{e}$, we remark that:

$$
U^{T}(\tau) \geqslant U^{e}(\tau) \Leftrightarrow \frac{\left(\phi \gamma^{T}+\alpha \delta+\rho-\tau \omega\right)^{\beta}}{\left(\phi \gamma^{e}+\alpha \delta+\rho\right)^{\beta}} \geqslant \frac{\rho-\beta \gamma^{T}}{\rho-\beta \gamma^{e}}
$$

This condition (30) depends on parameters both present in individual preferences and production side. This means that for the same government size $\tau$, the social welfare corresponding to growth under lump-sum tax is not necessarily higher than the social welfare corresponding to growth under income tax although the growth rate under lump-sum tax is always higher than the growth rate under income tax.

Figure 1 illustrates Proposition 1 with specific numerical values for the parameters verifying transversality condition (14) and positivity of growth rates. The increasing dotted curve in Figure 1a represents the decentralized 


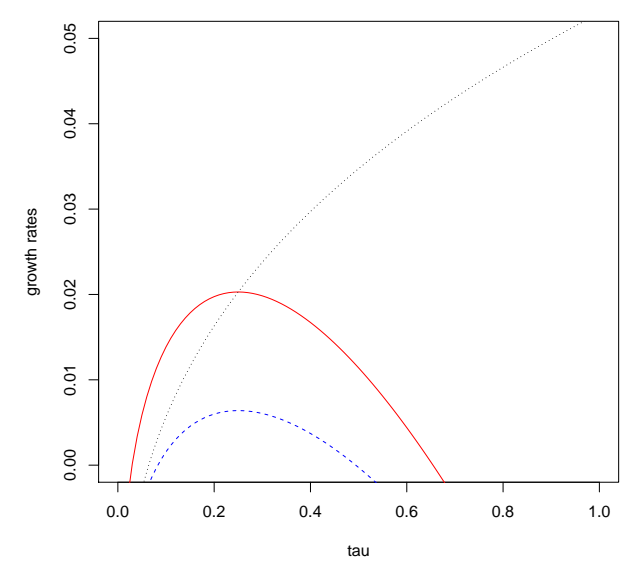

(a)

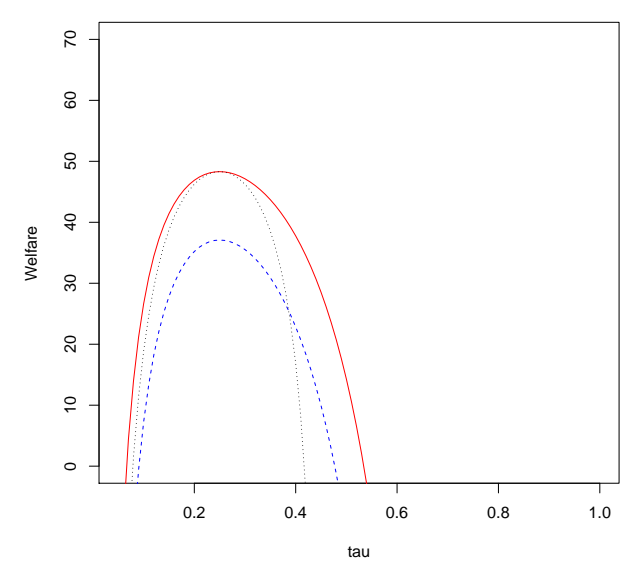

(b)

Figure 1: Growth rate and welfare as functions of government size $\tau$. Parameter values which verify transversality condition (14) and positivity of growth rates are: $\alpha=0.25, \sigma=0.5, \rho=0.01, \delta=0.05, s=0.3, A^{\frac{1}{1-\alpha}}=0.2$.

growth rate under lump-sum tax $\gamma^{T}$ (equation 18)), the dashed curve represents the decentralized growth rate under income tax $\gamma^{e}$ (equation (9)) and the solid curve represents the optimal growth rate $\gamma^{o}$ (equation (21)). We observe that the optimal growth is always higher than the decentralized rate under income tax whatever the value of $\tau$. This is due to the fact that the private marginal product of capital is always lower than the social marginal product of capital $f_{k}^{o}$. Concerning the decentralized rate under lump-sum tax, it is increasing with $\tau$. It is lower than the optimal growth rate for all government size $\tau$ lower than its optimal growth-maximizing value $\hat{\tau}$, and it is all the more divergent from the optimal rate that $\tau$ is higher than its optimal growth-maximizing value $\hat{\tau}$. In particular, it can meet the maximum value of the optimal growth, when the government size is optimally set, i.e. $\hat{\tau}=\alpha=0.25$.

The result illustrated by Figure 1a is similar to that in a conventional model without status-seeking. It is explained by the fact that we are considering a social planner which respects individal preferences and as in the conventionnal model, the only difference between private agents' decisions and social planner's decisions is located at the internalization of externalities made by the social planner. This difference does result in a difference between decentralized growth rates (depending on the private marginal product of capital) and optimal growth rate (depending on the social marginal product of capital). In 
a decentralized economy, if public spending is financed by an income tax, there are a fiscal distortion, implying a disincentive to invest and a distortion, caused by public spending externality. The latter is variable and may be positive or negative following the value of government size $\tau$ which can be lower or higher than $\hat{\tau}$. If government size is $\tau=\frac{G}{y}<\alpha$, agents should invest more. Distortion caused by public spending externality corresponds to an under-investment. On the contrary, if $\tau=\frac{G}{y}>\alpha$, then agents should invest less. Distortion caused by public spending externality corresponds to an over-investment. This explains why under lump-sum tax, when fiscal distortion disappears, the growth rate under lump-sum tax is higher than that under income tax. As well as, the more $\tau$ is higher than $\alpha$, the higher the growth is under lump-sum tax. When the government size is optimally set, public spending externality disappears and under lump-sum tax, the fiscal distortion disappears as well. Therefore, only the lump-sum tax is a measure to restore the optimal growth in a decentralized economy.

When observing Figure 1b which illustrates social welfares $U^{e}(\tau)$ under income tax, $U^{T}(\tau)$ under lump-sum tax and optimal social welfare $U^{o}(\tau)$, for different values of government size, we remark that a very high growth rate under lump-sum tax may move the corresponding social welfare (the dotted curve) away from its optimal value (the solid curve). Besides, when the government size $\tau$ becomes too large, the social welfare obtained with a growth rate under lump-sum tax may be lower than the social welfare obtained with a growth rate under income tax (the dashed curve). Then, income tax may be preferred to lump-sum tax from the viewpoint of welfare when goverment size is sufficiently high. It should be noticed that the threshold of $\tau$ from which income tax gives a higher social welfare is determined from condition (30), then this threshold depends on parameters both present in individual preferences and production function.

\section{Status-seeking, growth and welfare}

This section focuses on the effects of status-seeking on the economic growth. Let us consider two different cases, RAJ and KUJ. In the first case, an increase in average consumption lowers the individual's marginal utility of his own consumption, $\frac{U_{c \bar{c}}}{U_{c}}=\frac{s}{c}\left(\frac{1}{\sigma}-1\right)<0$. This corresponds to $\sigma>1$. In the opposite case where individuals keep up with the Joneses, the effect of the average consumption on the individual's marginal utility of his own consumption is 
positive, $\frac{U_{c} \bar{c}}{U_{c}}=\frac{s}{c}\left(\frac{1}{\sigma}-1\right)>0$. This corresponds to $\sigma<1$. The following Proposition examines the relationship between the economic growth and the weight that individuals attache to their social status.

Proposition 2 Consider an economy where individual preference does exhibit the desire for social status, and economic growth rate under income tax is defined by equation (9) while economic under lump-sum tax is defined by equation (18). These growth rates are decreasing with the status weight if individuals run away from the Joneses, and increasing with the status weight if individuals keep up with the Joneses.

Proof 2 We differentiate (9) and (18) with respect to $s$. These first derivatives are negative for the case RAJ where $\sigma>1$ and positive for the case KUJ where $\sigma<1$.

This result is rather intuitive. Indeed, the desire to keep up with the Joneses means that others' consumption is considered as a complement for each individual's consumption. This implies that an economy with status-seeking behavior grows at a higher rate than an economy without status-seeking, and the growth rate is increasing with status weight.

Different from the keekping up with the Joneses, the desire to run away from the Joneses means that others' consumption is considered as a substitute for each individual's consumption. In this case, an economy with status-seeking behavior grows at a lower rate than an economy without status-seeking, and the growth rate is decreasing with status weight $s$.

Figure 2a illustrates the relationship between growth rates and status weight in the case of keeping up with the Joneses, i.e. $\sigma<1$. Choosing a governement size of 0.4 , we observe that the growth rate under lump-sum tax (the dotted curve) is higher than the growth rate under income tax (the dashed curve). However, the social welfare under lump-sum tax is lower as it is alreay illustrated in Proposition 1 and Figure 1b. For different values of status weight between 0 and 1, Figure $2 \mathrm{~b}$ shows that the dotted curve representing the social welfare under lump-sum tax is below the dashed curve which represents the social welfare under income tax.

It is not insignificant to note that social welfares in both cases (income and lump-sum tax) are decreasing with status weight (Figure 2b). Indeed, when observing both graphs in Figure 2, we remark that given elements from the supply side such as technological parameter, public spending, etc., a higher 


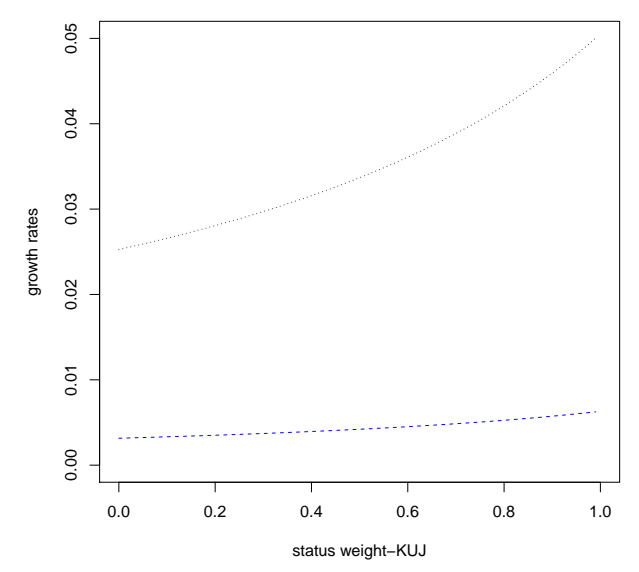

(a)

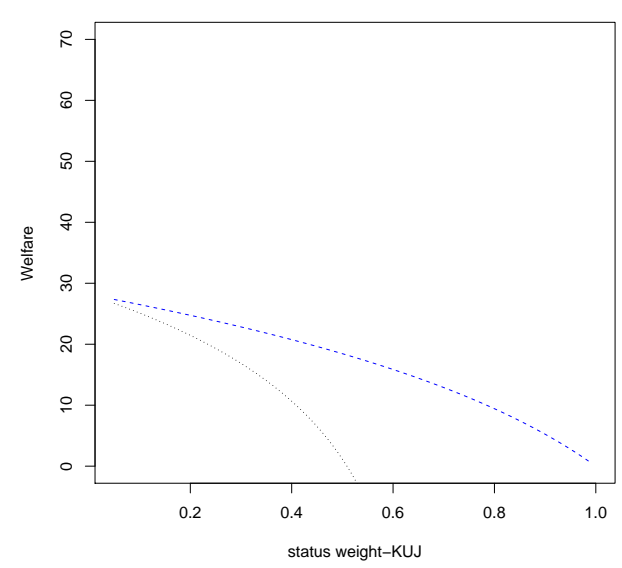

(b)

Figure 2: Growth rate and welfare as functions of status weight $s$ in case of keeping up with the Joneses. Parameter values which verify transversality condition (14) and positivity of growth rates are: $\tau=0.4, \alpha=0.25, \sigma=0.5, \rho=0.01, \delta=0.05, A^{\frac{1}{1-\alpha}}=$ 0.2 .

growth rate explained by a higher status motive may be accompanied by a lower social welfare. Then, social comparison accompanied by the keeping up with the Joneses may improve economic growth, but it does not necessarily make people happier. On the contrary, a higher growth rate which has its driver at the supply side, i.e. the productive public spending in this model, may improve individuals' welfare, given their preferences for social comparison. Indeed, as illutrated in Figure 1 the maximization of growth rate (with respect to government size) in case of income tax corresponds to the maximisation of social welfare.

\section{Conclusions}

This paper revisits Barro's growth model by taking into account individual desire for social status. In the presence of status-seeking, the desire to keep up with or run away from the Joneses influences individual behaviors and economic growth. We assume that public spending, as an input of the production process is financed by income tax or lump-sum tax. The results underline the individuals' preferences, in particular their desire for social status, as a key role in explaining long term economic growth and welfare. 
We discuss two public financing rules, income tax and lump-sum tax, from the viewpoint of growth and welfare. If lump-sum tax always implies a higher growth rate, income tax may perform better in terms of welfare than lump-sum tax. Besides, given individual preferences for social status, as in the standard growth model, a maximisation of growth under income tax corresponds to a maximization of social welfare. However, when considering elements from the supply side as given, a higher growth rate explained by a higher status-seeking accompanied by the keeping up with the Joneses corresponds to a lower social welfare. This inverse relationship between growth and welfare is then explained by the consideration of status-seeking and keeping up with the Joneses.

\section{References}

[1] Alvarez-Cuadrado, F., Casado J.M., Labeaga J.M. (2015), "Envy and Habits: Panel Data Estimates of Interdependent Preferences", Oxford Bulletin of Economics and Statistics, 0305-9049doi: 10.1111/obes.12111

[2] Aronsson, T. and Johansson-Stenman O. (2013), "Conspicuous Leisure: Optimal Income Taxation when Both Relative Consumption and Relative Leisure Matter", Scandinavian Journal of Economics, 115 (1), pp. 155-175.

[3] Barro, R.J (1990), "Government Spending in a Simple Model of Endogenous Growth", Journal of Political Economy, 98, pp. S103-S125.

[4] Barro, R. J. and Sala-i-Martin X. (2004), Economic Growth, second edition, MIT Press.

[5] Brekke, K.-A. and Howarth, R.B. (2002), Status, Growth and The Environment: Goods As Symbols in Applied Welfare Economics, Edward Elgar, Northampton.

[6] Carroll C., Overland J. and Weil D. N. (1997), "Comparison Utility in a Growth Model", Journal of Economic Growth, 2, pp. 339-367.

[7] Chang W. (2006), "Relative Wealth, Consumption Taxation, and Economic Growth", Journal of Economics, 2, pp. 103-129.

[8] Clark, A., Frijters P. and Shields M. (2008), "Relative Income, Happiness and Utility: An Explanations for Easterlin Paradox and Other Puzzles", Journal of Economic Literature, 46, pp. 95-144.

[9] Corneo, G. and Jeanne O. (1997), "Relative Wealth Effects and the Optimality of Growth", Economics Letters, 54, pp. 87-92. 
[10] Corneo, G. and Jeanne O. (2001), "On the Relative-Wealth Effects and Long-Run Growth", Research in Economics, 55, pp. 349-358.

[11] Duesenberry, J.S. (1949), Income, Saving and the Theory of Consumer Behaviour, Havard University Press, Cambridge (MA).

[12] Dupor B. et Liu W.-F. (2003), "Jealousy and Equilibrium Overconsumption", American Economic Review, pp. 423-428.

[13] Fafchamps M. et F. Shilpi (2008), "Subjective welfare, isolation, and relative consumption," Journal of Development Economics, 86(1), pp. 43-60.

[14] Ferrer-i-Carbonell, A. (2005), "Income and Well-Being : an Empirical Analysis of the Comparison Income Effect", Journal of Public Economics, 89, pp. 997-1019.

[15] Fisher, W. H. and Hof F. X. (2000), "Relative Consumption, Economic Growth and Taxation", Journal of Economics (Zeitschrift für Nationalökonomie), 73, pp. 241-262.

[16] Frijters, P., Shields M. and Haisken-Deneuw J. (2004), "Money Does Matter! Evidence from Increasing Real Incomes in East Germany following Reunification", American Economic Review, 94, pp. 730-741.

[17] Galí J. (1994), "Keeping up with the Joneses: Consumption Externalities, Portfolio Choice, and Asset Prices", Journal of Money, Credit and Banking, 26 (1), pp. 1-8.

[18] Glomm G. and Ravikumar B. (1994), "Growth-Inequality Trade-offs in a Model with Public Sector R-D", Canadian Journal of Economics, 27, pp. 485-493.

[19] Gómez, M. (2006), "Optimal Consumption Taxation in a Model of Endogenous Growth with External Habit Formation", Economics Letters, 93, pp. 427-435.

[20] Johansson-Stenman, O., Carlsson F. , and Daruvala D. (2002), "Measuring Hypothetical Grandparents, Preferences for Equality and Relative Standing", Economic Journal, 112, pp. 362-83.

[21] Lau, S.-H. P. (1995), "Welfare-maximizing vs. growth-maximizing shares of government investment and consumption", Economics Letters, 47 (issue 3-4), pp. 351-359. 
[22] Liu, W.-F . and Turnovsky, S.J (2005), "Consumption Externalities, Production Externalities and Long-Run Macroeconomic Efficiency", Journal of Public Economics, 89, pp. 1097-1129.

[23] Long, N.V and Shimomura K. (2004), "Relative Wealth, Status Seeking and Catching-Up", Journal of Economic Behavior and Organization, 53, pp. $529-542$.

[24] Mangasarian, O.L. (1966), "Sufficient Conditions for the Optimal Control of Nonlinear Systems", SIAM Journal of Control, 4, pp.139-152.

[25] Marrero, G.A. and Novales A. (2005), "Growth and Welfare: Distorting versus Non-Distorting Taxes", Journal of Macroeconomics, 27, pp.403-433.

[26] McBride, M. (2001), "Relative-Income Effects on Subjective Well-Being in the Cross-Section", Journal of Economic Behavior and Organization, 45, pp. 251-278.

[27] Ng, Y.K (2003), "From Preferences to Happiness: Towards a more Complete Welfare Economics", Social Choice and Welfare, 20, pp. 307-350.

[28] Nguyen-Van, P. and Pham, T.K.C. (2013), "Endogenous fiscal policies, environmental quality, and status-seeking behavior", Ecological Economics, 88, pp. 32-40.

[29] Pham, T.K.C. (2005), "Economic Growth and Status-Seeking through Personal Wealth", European Journal of Political Economy, 21, pp. 407-427.

[30] Rauscher, M. (1997), "Conspicuous Consumption, Economic Growth and Taxation", Journal of Economics (Zeitschrift für Nationalökonomie), 66, pp. 35-42.

[31] Turnovsky, S.J. and Monteiro, G. (2007), "Consumption Externalities, Production Externalities and Efficient Capital Accumulation under Time non-Separable Preferences", European Economic Review, 51, pp. 479-504.

[32] Vendrik, M. and Woltjer G.B. (2007), "Hapiness and Loss aversion: Is Utility Concave or Convex in Relative Income?", Journal of Public Economics, 91, pp. 1423-1448.

[33] Wendner, R. (2003), "Status, Environmental Externality, and Optimal Tax Programs", Economics Bulletin, 5, pp. 1-10.

[34] Wendner, R. (2010), "Growth and Keeping up with the Joneses", Macroeconomic Dynamics, 14, pp. 176-199. 